Gut, 1969, 10, 543-548

\title{
A relation between gastroduodenal muscle contractions and gastric emptying
}

\author{
N. W. WEISBRODT, J. N. WILEY, B. F. OVERHOLT ${ }^{1}$, AND PAUL BASS \\ From the University of Michigan Medical Center, and Parke, Davis and Company \\ Research Laboratories, Ann Arbor, Michigan, USA
}

Studies of gastric emptying in dogs, rats, and man have demonstrated that solutions of various substances empty in a characteristic manner. This topic has been reviewed by Hunt (1963). The rate of emptying of test meals from the stomach is influenced by many factors, including volume (Hunt and Macdonald, 1954), osmotic pressure (Hunt, 1956), titratable acidity (Hunt and Knox, 1962), and chemical composition (Elias, Gibson, Greenwood, Hunt, and Tripp, 1968; Hunt and Knox, 1968).

Thomas (1957) has reviewed motor patterns of the gastroduodenal area which have been characterized when various substances are placed in the stomach. These studies were usually done with balloons or open-tip catheters. Such devices are obstructive to the normal flow of gastric contents and may initiate reflexes that can alter gastric emptying time. Radiological methods have also been used but the data obtained by these methods are subjective and difficult to quantify. Louckes, Quigley, and Kersey (1960) utilized the inductograph, an extraluminal recording device, to study the contractile pattern of the 'pyloric region' but did not quantify their results. Another type of extraluminal device has been developed (Jacoby, Bass, and Bennett, 1963). This unit avoids mucosal contact and the data obtained may be quantified.

In this study extraluminal force transducers were used to monitor gastric and duodenal smooth muscle contractions in intact unaesthetized dogs. The gastric emptying rate of trisodium citrate and glucose and that of the fat substance test meals and their influence on smooth muscle contractions were evaluated.

\section{METHODS}

TEST MEALS Gastric emptying was measured in five male beagle dogs weighing between 8 and $12 \mathrm{~kg}$ by a modification of the Hunt technique (Hunt, 1959) using $\mathrm{Na}_{2}{ }^{51} \mathrm{CrO}_{4}$, $20 \mu \mathrm{c} / \mathrm{l}$, as the non-absorbable marker. Three test meals,

${ }^{1}$ Present address: Department of Internal Medicine, Section of Gastroenterology, New York Hospital, Cornell Medical Center. each having an osmotic pressure of 200 milliosmoles per litre as measured by freezing point depression, were used. They consisted of $39.2 \mathrm{~g} / 1$ glucose, $19.6 \mathrm{~g} / 1$ trisodium citrate (citrate test meal), or $19.0 \mathrm{~g} / 1$ trisodium citrate with $10 \mathrm{mN}$ oleic acid suspended by $0.5 \%$ Tween 80 (citrate-fat test meal). The initial $p \mathrm{H}$ readings of the citrate and citrate-fat test meals were similar $(7 \cdot 3$ to $6 \cdot 5)$ and the meals buffered due to the presence of the trisodium citrate; the glucose test meal had a lower initial $p \mathrm{H} \mathrm{(4 \cdot 6)}$ and was not buffered. The test meals were at room temperature $\left(25^{\circ} \mathrm{C}\right)$ when administered.

ANIMAL PREPARATIONS To facilitate the administration and aspiration of the test meals, an oesophageal cannula was implanted 10 days before the study. Animals were anaesthetized with pentobarbital $(30 \mathrm{mg} / \mathrm{kg})$ and a vitallium cannula (Austenal Inc, New York, NY) was passed aborally down the oesophagus flange first. This manoeuvre facilitated visualization and incision of the oesophagus. The neck end of the cannula was then brought through a small incision in the oesophagus and exteriorized. The presence of the cannula did not cause any visible discomfort to the animals and at necropsy only a localized area of inflammation was present in an otherwise normal oesophagus.

Contractile activity was monitored in the five dogs using extraluminal strain gauge force transducers. (Jacoby et al, 1963, and later modified by Anderson, Bolt, Ullman, and Bass, 1968a). These sensors allow repeated monitoring of smooth muscle contractile activity from chronic unanaesthetized animals. Contractile activity was monitored from the circular axes of the stomach body, the proximal and distal antrum, the duodenal cap, and the proximal duodenum. In this study, the longitudinal axes were not monitored. The average distances of the stomach transducers from the gastroduodenal junction (hypomuscular segment, Bass, Code, and Lambert, 1961) were $12 \cdot 5,5 \cdot 7$, and $3 \mathrm{~cm}$ respectively; the duodenal units were $2 \cdot 2$ and $7 \cdot 7 \mathrm{~cm}$ respectively. These measurements were taken at the time of necropsy.

EXPERIMENTAL PROCEDURE AND ANALYSIS OF DATA Following an 18-hour fast, the animal's stomach was washed with $100 \mathrm{ml}$ distilled water instilled through a tube placed in the stomach via the oesophageal cannula. This procedure evoked a burst type pattern of contractile activity 
CONTROL

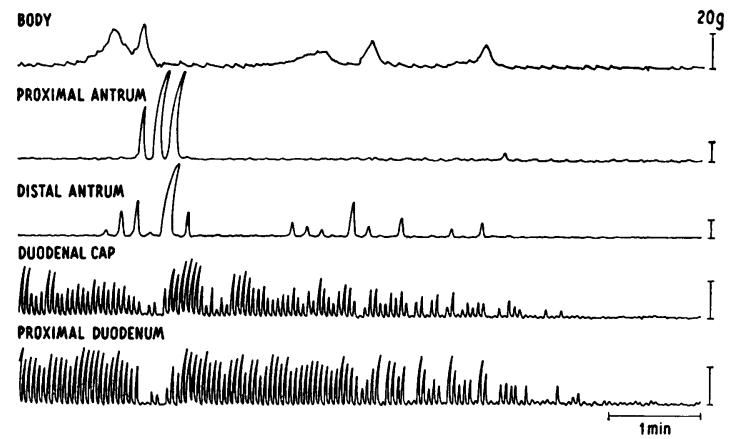

FIG. 1. Contractile patterns of the gastroduodenal area preceding the instillation of the initial test meal. For visual comparison the above and Fig. 3 were obtained from the same animal.

which lasted approximately 20 minutes followed by a basal period of activity (Fig. 1). Following the burst activity $300 \mathrm{ml}$ of one of the test meals was placed into the stomach by the gastric tube inserted through the oesophageal cannula and the tube removed. After a given time interval the tube was reinserted, the test meal aspirated, and the stomach rinsed with $50 \mathrm{ml}$ distilled water. The instillation and aspiration of the test meal were repeated three times per day at sequential time intervals of either 10,20, and $40 \mathrm{~min}$ or 40,20 , and 10 minutes. This sequence of administration and aspiration of test meals was repeated three times in each animal for each of the three test meals. Two replications were done before implantation of the gauges and one after implantation.

The activity and concentration of ${ }^{51} \mathrm{Cr}$ in the test meal, the aspirate, and the rinse were determined by counting a $10 \mathrm{ml}$ aliquot in a gamma counter. The volume of original meal remaining in the stomach was calculated by the formula

\section{Volume of original meal $=$

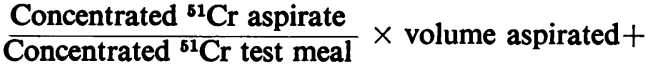

$$
\frac{\text { Concentrated }{ }^{51} \mathrm{Cr} \text { rinse }}{\text { Concentrated }{ }^{51} \mathrm{Cr} \text { test meal }} \times \text { volume rinse }
$$

The volume of endogenous secretions consisting of gastric secretion, swallowed salivary secretion, and refluxed duodenal content (rarely present) was also determined by use of the marker technique (Hunt, 1959). The precision of determining the volume of secretion using the marker method is difficult to assess because of two assumptions: the concentration of marker falls linearly with time and the homogeneous mixing of gastric contents. The $p \mathrm{H}$ of the test meals and of the aspirated solutions was determined using $\mathrm{pHydrion}$ paper.

Contractile activity was quantified in three of the five dogs over the time required for the total gastric contents to be reduced to $150 \mathrm{ml}\left(\mathrm{t}_{\mathrm{t}}\right)$. Three methods were used to quantify the data. (1) The percentage activity obtained by counting all the contractions over $5 g$ force occurring during the $t_{\frac{1}{2}}$ and dividing by the number of contractions that would have occurred if the muscle were contracting at its maximal frequency. The maximal frequency was obtained from a period of burst activity. (2) A 'motility index' which is an arbitrary scoring system for measuring the force of contractions as calculated by the method of Jacoby and Brodie (1967). Briefly, the amplitudes of contraction were arbitrarily divided into five levels, 5-10, 10-20, 20-40, 40-80, and over $80 \mathrm{~g}$ force. Transparent templates were applied to the records, and the contractions falling into each of the above levels for each $t_{1}$ were counted. The number of contractions at each level was multiplied by an arbitrary value proportional to the force range. These values were 5-10 $g=1,10-20 g=2$, 20-40 $g=4,40-80 g=8$, and $>80 g=16$. These values were then summed and expressed as the 'motility index'. (3) A 'motility index'/minute obtained by dividing the motility index by the $t_{\frac{1}{2}}$.

A four-way analysis of variance (Chilton, 1960) with respect to dogs, test meals, time intervals, and replications was used to analyse the gastric emptying data. A one-way analysis of variance was utilized to analyse the contractile activity data. Duncan's multiple range test was used to determine the differences between the means (Duncan, 1955).

\section{RESULTS}

GASTRIC EMPTYING OF ORIGINAL TEST MEALS The exponential pattern of gastric emptying is presented on a plot of log volume of original meal remaining in the stomach with respect to time (Fig. 2). A

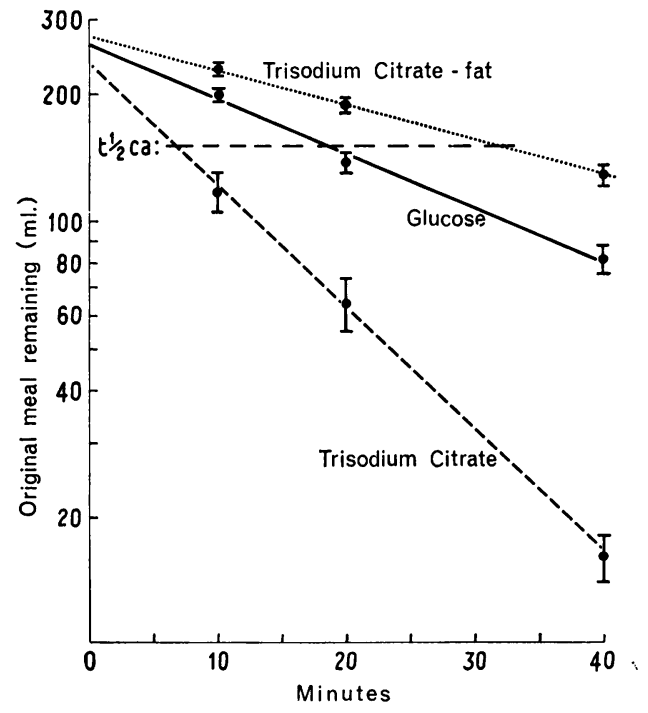

FIG. 2. Gastric emptying of $300 \mathrm{ml}$ of three test meals. Vertical bars denote standard error. Each mean represents 15 test meals. A total of 135 test meals were used. The halflives were approximately 7,18 , and 32 minutes. 
TABLE I

MEAN ENDOGENOUS SECRETIONS ${ }^{1}$ AND FINAL $^{2} p$ H OF TEST MEALS $^{2}$

\begin{tabular}{|c|c|c|c|c|c|c|c|c|c|}
\hline & \multicolumn{3}{|l|}{ Citrate } & \multicolumn{3}{|l|}{ Glucose } & \multicolumn{3}{|l|}{ Citrate-fat } \\
\hline & $10 \mathrm{~min}$ & $20 \mathrm{~min}$ & $40 \mathrm{~min}$ & $10 \mathrm{~min}$ & $20 \mathrm{~min}$ & $40 \mathrm{~min}$ & $10 \mathrm{~min}$ & $20 \mathrm{~min}$ & $40 \mathrm{~min}$ \\
\hline
\end{tabular}

${ }^{1}$ Total volume of endogenous secretions (see methods)

${ }^{2}$ The initial $p \mathrm{H}$ for the three test meals were $7 \cdot 3,4 \cdot 6$, and 6.5 respectively

3 itandard error of the mean

negative starting index for all three test meals indicates that $300 \mathrm{ml}$ placed in a dog's stomach elicits a rapid initial emptying that deviates from the exponential pattern.

The four-way analysis of variance on the gastric emptying data indicates that: (1) the volume of the three test meals decreases significantly over time $(P<0.01) ;(2)$ there was a significant difference in the rate of emptying among the three test meals $(P<0.01)$. The Duncan multiple range test revealed that each of the three test meals differed significantly from each other in their rate of emptying (citrate > glucose > citrate-fat); (3) there was no significant difference between the three replications of each of the test meals $(P>0.05)$. This lack of significance among the three replications indicates that the presence of the transducers did not alter the gastric emptying time, since two of the emptying experiments were performed before and one after the transducers were implanted.

ENDOGENOUS SECRETIONS The citrate test meal elicited a larger volume of endogenous secretions than the glucose or citrate-fat test meals (Table I). The $p \mathbf{H}$ of the aspirated citrate and citrate-fat test meals was not markedly lowered; in contrast, the aspirated glucose solutions had a $p \mathrm{H}<2 \cdot 5$.

HALF-LIFE $\left(\mathrm{T}_{\frac{1}{2}}\right)$ Since the motility patterns would respond to total gastric contents, the motility data were analysed over the time period for the total gastric contents, that is the meal plus secretion, to be reduced to $150 \mathrm{ml}$. These three half-lives were 10 , 25 , and 40 minutes for citrate, glucose, and citratefat test meals. The half-lives for the original test meals leaving may be obtained from Figure 2 . These latter half-lives are shorter than the time required to reduce the total gastric contents to $150 \mathrm{ml}$.

CONTRACTILE ACTIVITY The burst pattern was followed by a basal pattern which was characteristic of the interdigestive state and is presented in Figure 1. Instillation of any of the three test meals during the basal period elicited no detectable tonal change in the gastric antrum; however, a slight $(<5 \mathrm{~g})$ accommodation of the gastric body was observed. (This accommodation represents a passive stretching of the gastric wall induced by the fluid; it has also been recorded in acute animal preparations and even shortly after sacrificing the animal.) During the remainder of the test period, only low amplitude

\section{TRISODIUM CITRATE}

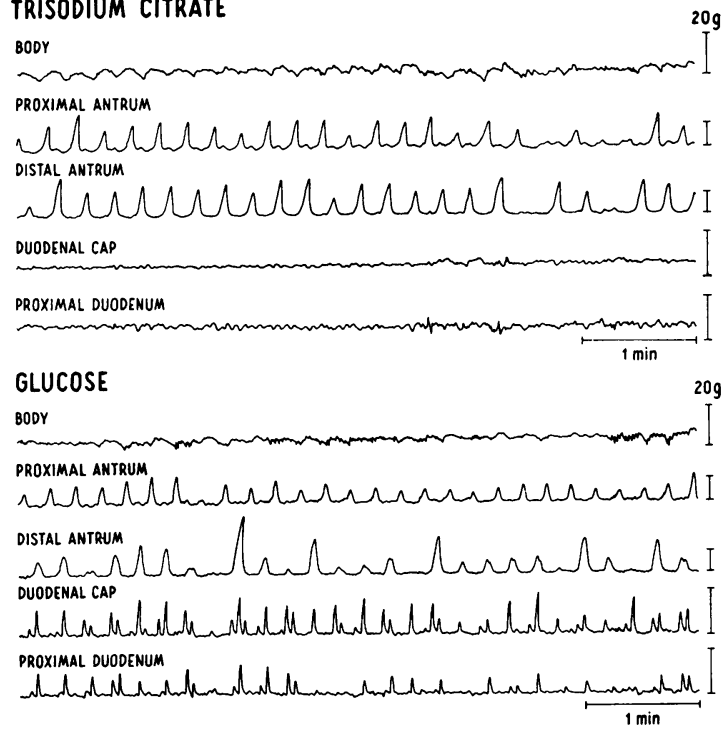

TRISODIUM CITRATE $\bar{c} 10 \mathrm{mN}$ OLEIC ACID

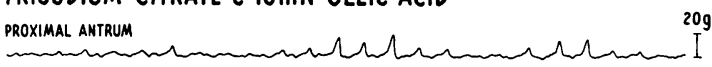

DISTAL ANTRUM

DisTAL ANTRUM DUODENAL CAP

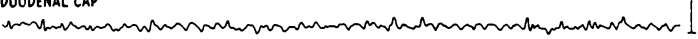
PROXIMAL DUODENUm

FIG. 3. Contractile patterns of the gastroduodenal area elicited by the three test meals. The records were obtained from the same animals five minutes after administration. Note the relatively high antral to low duodenal activity elicited by the citrate test meal (upper record) and the reversed relationship induced by the addition of fat (lower record). 
TABLE IIa

CONTRACTILE ACTIVITY AFTER INSTILLATION OF TEST MEALS ${ }^{1}$

\begin{tabular}{|c|c|c|c|c|c|c|c|c|c|}
\hline \multirow{2}{*}{ Site } & \multicolumn{3}{|c|}{ Activity $(\%)$} & \multicolumn{2}{|l|}{ Motility Index } & \multicolumn{4}{|c|}{ Motility Index/Minute } \\
\hline & Citrate & Glucose & $\begin{array}{l}\text { Citrate } \\
\text { Fat }\end{array}$ & Glucose & $\begin{array}{l}\text { Citrate } \\
\text { Fat }\end{array}$ & Citrate & Glucose & $\begin{array}{l}\text { Citrate } \\
\text { Fat }\end{array}$ & $F$ \\
\hline $\begin{array}{l}\text { PA } \\
\text { DA } \\
\text { DC } \\
\text { PD }\end{array}$ & $\begin{array}{c}81 \cdot 8 \pm 4 \cdot 9^{3} \\
70 \cdot 4 \pm 5 \cdot 1 \\
2 \cdot 3 \pm 1 \cdot 4 \\
3 \cdot 0 \pm 1 \cdot 1\end{array}$ & $\begin{array}{r}56 \cdot 8 \pm 8 \cdot 8 \\
49 \cdot 6 \pm 11 \cdot 0 \\
6 \cdot 6 \pm 3 \cdot 9 \\
15 \cdot 6 \pm 3 \cdot 5\end{array}$ & 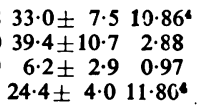 & $\begin{array}{rr}90.8 \pm 5.0 & 144.6 \pm 28 \cdot 5 \\
166.4 \pm 48.2 & 185.4 \pm 43 \cdot 5 \\
0.80 \pm 0.6 & 49.8 \pm 30 \cdot 1 \\
5.40 \pm 2.1 & 90.2 \pm 41 \cdot 7\end{array}$ & $\begin{array}{rr}119.3 \pm 33.8 & 1.18 \\
281.2 \pm 110.8 & 0.69 \\
78.0 \pm 42.9 & 1.67 \\
307.0 \pm 57.8 & 19.65^{4}\end{array}$ & $\begin{array}{r}9 \cdot 1 \pm 0 \cdot 5 \\
16 \cdot 6 \pm 4 \cdot 8 \\
0 \cdot 1 \pm 0 \cdot 1 \\
0 \cdot 5 \pm 0 \cdot 2\end{array}$ & $\begin{array}{l}4 \cdot 8 \pm 1 \cdot 0 \\
6 \cdot 2 \pm 1 \cdot 4 \\
1 \cdot 7 \pm 1 \cdot 0 \\
3 \cdot 0 \pm 0 \cdot 6\end{array}$ & $\begin{array}{c}3 \cdot 0 \pm 0 \cdot 8 \\
7 \cdot 1 \pm 2 \cdot 8 \\
1 \cdot 9 \pm 1 \cdot 1 \\
7 \cdot 7 \pm 1 \cdot 4\end{array}$ & $\begin{array}{r}15 \cdot 62^{4} \\
3 \cdot 07 \\
1 \cdot 34 \\
14 \cdot 34^{4}\end{array}$ \\
\hline
\end{tabular}

TABLE IIb

THE DIFFERENCES BETWEEN THE MEANS DETERMINED BY DUNCAN'S MULTIPLE RANGE TEST

\begin{tabular}{|c|c|c|c|c|c|c|c|c|c|}
\hline \multirow{2}{*}{ Site } & \multicolumn{3}{|c|}{ Activity $(\%)$} & \multicolumn{3}{|c|}{ Motility Index } & \multicolumn{3}{|c|}{ Motility Index/Minute } \\
\hline & Citrate & Glucose & $\begin{array}{l}\text { Citrate } \\
\text { Fat }\end{array}$ & Citrate & Glucose & $\begin{array}{l}\text { Citrate } \\
\text { Fat }\end{array}$ & Citrate & Glucose & $\begin{array}{l}\text { Citrate } \\
\text { Fat }\end{array}$ \\
\hline PA & Citrate & Glucose & Citrate fat ${ }^{1}$ & & & & Citrate & Glucose & Citrate fat \\
\hline PD & Citrate & Glucose & Citrate fat & Citrate & Glucose & Citrate Fat & Citrate & Glucose & Citrate fat \\
\hline
\end{tabular}

${ }^{1}$ Any two means not underscored by the same line are significantly different at $p=0.05$

$\mathbf{P A}=$ proximal antrum; $\mathbf{P D}=$ proximal duodenum

contractile activity $(<5 \mathrm{~g})$ was recorded from the gastric body (Fig. 3). In contrast, high amplitude contractions were recorded from the gastric body during the interdigestive state (Fig. 1). The contractile activity of the gastric body was not quantified because of the low activity during the test periods.

Examples of contractile activity of the antralduodenal area following instillation of the three test meals are presented in Figure 3. The numerical analysis is presented in Table II. The analysis of the percentage activity (a measure of the presence of contractions over $5 g$ force) indicated that (1) in the proximal antrum the citrate test meal elicited a significantly higher percentage of activity than the citrate-fat test meal $(81.8 \%$ vs $33.0 \%, \mathrm{P}<0.01)$. The glucose test meal had an intermediate effect on the proximal antrum that was not significantly different from either the citrate or the citrate-fat test meal. (2) The percentage activity of the distal antrum was similarly influenced by the three test meals but the analysis of the data did not indicate significance at the 0.05 level. (3) The duodenal cap area was less active than the other areas monitored regardless of the test meal instilled. (4) In contrast to the antrum, the proximal duodenum in response to the citrate-fat test meal had a significantly higher percentage activity than in response to the citrate test meal $(24.4 \%$ vs $3.0 \%, \mathrm{P}<0.01)$. The glucose test meal had an intermediate effect that was not significantly different from either the citrate or citrate-fat test meal.
The analysis of the 'motility index' (a measure of contractile force during each $t_{\frac{1}{2}}$ ) denoted that in the proximal duodenum there was a significant difference in force elicited among the three test meals (citratefat $307.0>$ glucose $90.2>$ citrate 5.4). There was no significant change in the 'motility index' elicited among the three test meals at the other areas monitored.

The analysis of the 'motility index'/min (a measure of contractile force per minute) disclosed that this parameter changed in the same manner as the percentage activity.

The ratio of contractile activity of the proximal antrum to the proximal duodenum for each of the three methods of quantification was much greater than 1 for the citrate test meal and closer to or less than 1 for the citrate-fat test meal. For example, the ratio of the percentage activity elicited by the citrate test meal was $\frac{81 \cdot 8}{3.0}=27 \cdot 3$ compared to $\frac{33.0}{24.4}=1.4$ elicited by the citrate-fat test meal. The glucose test meal ratio was intermediate between that of the other two test meals.

\section{DISCUSSION}

The gastric emptying results obtained with the three test meals paralleled those of previous observations (Hunt, 1963). All three test meals emptied in an exponential manner at significantly different rates. The rate of gastric emptying of the citrate-fat test 
meal was lower than the citrate test meal. This is presumably due to the presence of the fat substances, since the initial $p \mathrm{H}$, temperature, osmotic pressure, volume, buffering capacity, and concentration of trisodium citrate were similar (the fat substances contributed little to the total osmotic pressure). The decrease in the rate of gastric emptying of the glucose test meal is probably due to the glucose rather than the presence of the acidic secretions mixed with the unbuffered test meal. Though the $p \mathrm{H}$ of the aspirated gastric contents following the glucose test meal was approximately $p \mathrm{H} 2 \cdot 0$, the threshold for $\left(\mathrm{H}^{+}\right)$in slowing gastric emptying is higher (Hunt, personal communication).

The patterns of gastric and duodenal contractile activity recorded in the interdigestive and digestive states from the unanaesthetized dog have been described (Reinke, Rosenbaum, and Bennett, 1967). The basal and burst patterns we recorded during the interdigestive state were similar to those reported. The pattern elicited by the citrate-fat test meal was qualitatively similar to the pattern elicited by $200 \mathrm{~g}$ canned dog food in their study (Fig. 13, Reinke et al, 1967), that is, a pattern characterized by relatively low antral activity accompanied by relatively high duodenal activity. The low and variable contractile activity of the duodenal cap area relative to the proximal duodenum is in agreement with the variation of electrical activity between these segments (Bass et al, 1961).

The contractile pattern elicited by the citrate test meal which is rapidly emptied from the stomach is characterized by relatively high antral and low duodenal activity. In contrast, the citrate-fat test meal empties slowly and elicits a contractile pattern characterized by relatively low antral and high duodenal activity. Since the volumes of the test meals plus secretion emptied from the stomach during each $t_{\frac{1}{2}}$ are known (citrate $210 \mathrm{ml} v s$ citratefat $195 \mathrm{ml}$ ) and the number of proximal antral contractions during these periods is also known (citrate $45 v s$ citrate-fat 67), the average emptying stroke volume can be calculated (citrate $4.7 \mathrm{ml} v s$ citratefat $2.9 \mathrm{ml}$ ). The antrum, in addition to moving material into the duodenum, also moves material back into the gastric body (Carlson, Code, and Nelson, 1966). Our present study did not allow quantification of this retropulsion.

The relation of gastric emptying time to contractile activity may be such that the differences in emptying time and average stroke volume are due to: (1) a decrease in the average contractile force of the antrum ('motility index'/min data). This ability of fat substances to decrease but not completely inhibit antral activity has been shown by Smith and Code (1958) and by Anderson, Bolt, Ullman, and Bass (1968b); or (2) an increase in the resistance of the duodenum to the reception of the test meal ('motility index' data). The ability of increased contractile activity to inhibit the flow of material into the zone of contraction has been documented by Connell (1962) for the colon and by Ludwick, Wiley, and Bass (1968) for a reversed segment of duodenum. In addition, Gregory (1950) demonstrated that the presence of a meal in a dog's stomach caused increased jejunal loop activity and increased resistance to flow through the loop.

The interpretation of our data suggests that material empties from the stomach when the antrum is contracting and the duodenum is quiet. Since the antral contractions and the duodenal quiescence are intermittent during gastric emptying of the citrate-fat test meal, the emptying time of the citratefat test meal is longer than for the citrate test meal which elicits almost continuous antral contractions but almost no duodenal contractions.

The data obtained during emptying of the citrate test meal indicate a direct relationship between the contractions of the antral musculature and the exponential rate of gastric emptying. The motility index calculated for the $0-5,5-10$, and 10-15-minute intervals following instillation of the citrate test meal was $53.7 \pm 0.3,32.7 \pm 2 \cdot 8$, and $25.3 \pm 7.6$ respectively. Thus the greater the activity of the antrum, the greater the rate of gastric emptying. A similar analysis for the glucose and citrate-fat test meals was complicated by the presence of the duodenal activity.

The control of gastric emptying can be adequately explained by the relation of the contractions between the antrum and duodenum. Since the gastric body did not dramatically respond to any of the test meals, it apparently functions mainly as a 'reservoir'. Further the contractility data do not reveal any evidence for the presence of a unique function for the terminal antrum or the presence of a 'sphincter'. The integrated contractile activity of the antralduodenal area has been documented previously for emptying of solid material by McCoy and Bass (1963), and for a barium meal by Carlson et al (1966).

\section{SUMMARY}

This study was undertaken to characterize the antral and duodenal contractile activity patterns during gastric emptying of three test meals. Contractile activity was monitored by extraluminal strain gauge force transducers and gastric emptying was measured using serial test meals. The gastric emptying of a 200 milliosmol test meal of trisodium citrate was significantly more rapid than equal osmolar test 
meals of glucose or trisodium citrate with $10 \mathrm{mN}$ oleic acid. The contractile activity of the gastric antrum was higher during emptying of the citrate test meal as compared to the other two test meals. In contrast the contractile activity of the duodenum was significantly higher for the citrate-fat and glucose test meals as compared with the citrate test meal. These data indicate that gastric emptying is regulated in part by the relative contractile force of the antrum and duodenum. The exponential emptying rate of the stomach is directly related to the force of the antrum (as seen with the citrate test meal). The duodenal contractile activity also influences gastric emptying (as seen with the citrate-fat test meal). The greater rate of emptying occurs when there is relatively high antral and low duodenal activity; conversely, the slowest emptying occurs when there is relatively low antral and high duodenal activity.

\section{REFERENCES}

Anderson, J. J., Bolt, R. J., Ullman, B. M., and Bass, P. (1968a). Differential response to various stimulants in the body and antrum of the canine stomach. Amer. J. dig. Dis., 13, 147-156.

,,---1 (1968b). Effect of bile and fat on gastric motility under the influence of various stimulants. Ibid., 13, 157-167.

Bass, P., Code, C. F., and Lambert, E. H. (1961). Electric activity of gastroduodenal junction. Amer. J. Physiol., 201, 587-592.

Carlson, H. C., Code, C. F., and Nelson, R. A. (1966). Motor action of the canine gastroduodenal junction: a cineradiographic, pressure, and electric study. Amer. J. dig. Dis., 11, 155-172.

Chilton, N. W. (1960). Studies in the design and analysis of dental experiments. II. A four-way analysis of variance. I. dent. Res., 39, 344-360.
Connell, A. M. (1962). The motility of the pelvic colon. II. Paradoxical motility in diarrhoea and constipation. Gut, 3, 342-348.

Duncan, D. M.(1955). Multiple range and multiple F tests. Biometrics, 11, 1-42.

Elias, E., Gibson, G. J., Greenwood, L. F., Hunt, J. N., and Tripp, J. H. (1968). The slowing of gastric emptying by monosaccharides and disaccharides in test meals. J. Physiol. (Lond.), 194, 317-326.

Gregory, R. A. (1950). Some factors influencing the passage of fluid through intestinal loops in dogs. Ibid., 111, 119-137.

Hunt, J. N. (1956). Some properties of an alimentary osmoreceptor mechanism. Ibid., 132, 267-288.

- (1959). Gastric emptying and secretion in man. Physiol. Rev., 39, 491-533.

- (1963). The duodenal regulation of gastric emptying. Gastroenterology, 45, 149-156.

- , and Knox, M. T. (1962). The regulation of gastric emptying of meals containing citric acid and salts of citric acid J. Physiol. (Lond.), 163, 34-45.

- -1 (1968). A relation between the chain length of fatty acids and the slowing of gastric emptying. Ibid., 194, 327-336.

-, and Macdonald, I. (1954). The influence of volume on gastric emptying. Ibid., 126, 459-474.

Jacoby, H. I., Bass, P., and Bennett, D. R. (1963). In vivo extraluminal contractile force transducers for gastrointestinal muscle. J. appl. Physiol., 18, 658-665.

clopramide. Gastroenterology, 52, 676-684.

Louckes, H. S., Quigley, J. P., and Kersey, J. (1960). Inductograph method for recording muscle activity, especially pyloric sphincter physiology. Amer. J. Physiol., 199, 301-310.

Ludwick, J. R., Wiley, J. N., and Bass, P. (1968). Extraluminal contractile force and electrical activity of reversed canine duodenum. Gastroenterology, 54, 41-51.

McCoy, E. J., and Bass, P. (1963). Chronic electrical activity of gastroduodenal area: effects of food and certain catecholamines. Amer. J. Physiol., 205, 439-445.

Reinke, D. A., Rosenbaum, A. H., and Bennett, D. R. (1967). Patterns of dog gastrointestinal contractile activity monitored in vivo with extraluminal force transducers. Amer. J. dig. Dis., 12, 113-141.

Smith, A. W. M., and Code, C. F. (1958). The effect of an ordinary and of an excessively fatty breakfast on human gastric antral motility. Gastroenterology, 35, 398-405.

Thomas, J. E. (1957). Mechanics and regulation of gastric emptying. Physiol. Rev., 37, 453-474. 